\title{
Opposite effect of capsaicin and capsazepine on behavioral thermoregulation in insects
}

\author{
Justyna Olszewska • Eugenia Tegowska
}

Received: 8 March 2011/Revised: 26 May 2011/Accepted: 27 May 2011/Published online: 11 June 2011

(C) The Author(s) 2011. This article is published with open access at Springerlink.com

\begin{abstract}
Transient receptor potential channels are implicated in thermosensation both in mammals and insects. The aim of our study was to assess the effect of mammalian vanilloid receptor subtype 1 (TRPV1) agonist (capsaicin) and antagonist (capsazepine) on insect behavioral thermoregulation. We tested behavioral thermoregulation of mealworms larvae intoxicated with capsaicin and capsazepine in two concentrations $\left(10^{-7}\right.$ and $\left.10^{-4} \mathrm{M}\right)$ in a thermal gradient system for 3 days. Our results revealed that in low concentration, capsaicin induces seeking lower temperatures than the ones selected by the insects that were not intoxicated. After application of capsazepine in the same concentration, the mealworms prefer higher temperatures than the control group. The observed opposite effect of TRPV1 agonist and antagonist on insect behavioral thermoregulation, which is similar to the effect of these substances on thermoregulation in mammals, indicates indirectly that capsaicin may act on receptors in insects that are functionally similar to TRPV1.
\end{abstract}

Keywords Behavioral thermoregulation - Capsaicin . Capsazepine · TRPV1 - Mealworms

\section{Introduction}

The transient receptor potential family is widely involved in many sensory processes, with a subset of channels implicated in the reception of temperatures. They are

J. Olszewska (ه) - E. Tęgowska

Department of Animal Toxicology, Institute of General and Molecular Biology, Nicolaus Copernicus University, ul. Gagarina 9, 87-100 Toruń, Poland

e-mail: ojustyna@doktorant.umk.pl named thermoTRP and are responsible for thermosensation (Patapoutian 2005). In mammals, there are six thermoTRPs: two activated by cold (TRPM8 and TRPA1) and four activated by heat (TRPV1-4) (Dhaka et al. 2006). The first known receptor in mammals activated by noxious heat was vanilloid receptor subtype 1 (TRPV1) (Caterina et al. 1997). In humans, TRPV1 is widely expressed in neuronal (dorsal root ganglion, trigeminal ganglion and various brain regions including hypothalamus or hippocampus) and nonneuronal tissues (among others, urinary bladder, liver or macrophages) (Vennekens et al. 2008). Vanilloid receptor subtype 1 is a non-selective cation channel with substantial calcium permeability, activated by various chemical and physical stimuli. Chemical substances that activate the channel include various vanilloids (such as capsaicin) and endogenous lipid metabolites, while physical stimuli are acidic $\mathrm{pH}$ and high temperature $>43^{\circ} \mathrm{C}$ (O'Neil and Brown 2003; Benham et al. 2003). Other mammalian vanilloid receptors (TRPV2-4) also respond to warmth: TRPV2 is activated by noxious heat $\left(\sim 52^{\circ} \mathrm{C}\right)$, TRPV 3 opens at $34-39^{\circ} \mathrm{C}$ and TRPV4 at $25-34^{\circ} \mathrm{C}$ (Caterina 2007).

TRP receptors are also implicated in insects' thermosensation, especially the channels of the TRPA subfamily (McKemy 2007). Drospohila TRPA channels, on the contrary to mammalian TRPA, respond to warm temperatures (Dillon et al. 2009). Vanilloid receptors have also been discovered in insects (for details see: Olszewska 2010). These include two receptors found in Drosophila melanogaster: Nanchung and Inactive-calcium-permeable cation channels activated by mechanical and osmotic stimuli. Both receptors form one interdependent complex in the antennal chordotonal organ and are required for the insect's hearing (Gong et al. 2004; Liedtke and Kim 2005). 
In our research, we tried to assess the effect of TRPV1 agonist-capsaicin and antagonist-capsazepine on insect behavioral thermoregulation. Capsaicin is a natural alkaloid derived from pepper (Clapham 1997). Through activation of mammalian TRPV1, this substance causes a feeling of burning pain (Szallasi and Blumberg 1999). Consequently, capsaicin also affects animals' thermoregulation. Kobayashi et al. (1998) showed that this substance induces hypothermia in rats, which is afterward followed by hyperthermia. Preliminary studies at our laboratory revealed that capsaicin affects behavioral thermoregulation of the American cockroach Periplaneta americana-application of this vanilloid in submicromolar concentrations induced selection of lower temperatures in the thermal gradient system compared to cockroaches, which were not intoxicated (Adamkiewicz et al. 2008). Capsazepine, on the other hand, is a competitive antagonist of mammalian TRPV1 and it inhibits the organism's response to vanilloids (Walpole et al. 1994). It has been shown that administration of different TRPV1 antagonists induces hyperthermia in rats (Gavva et al. 2007).

The aim of our study was to assess the effect of capsaicin and capsazepine on insect thermoregulation. Based on our preliminary results on American cockroach, we hypothesized that capsaicin affects insect thermoregulation through receptors functionally similar to mammalian TRPV1 channel. To evaluate that, we examined behavioral thermoregulation of mealworms intoxicated with capsaicin and capsazepine in a thermal gradient system. We hypothesized that the examined insects would respond to the tested substances similarly to mammals, which means that capsaicin would induce seeking lower ambient temperatures by the insects and that capsazepine's action would be opposite.

\section{Materials and methods}

\section{Insects}

The mealworm larvae (Tenebrio molitor) were reared in room temperature and under 12:12 LD photoperiod in box containers filled with flour and oat flakes for hiding and as food. Slices of apples were provided at regular time intervals (every $24 \mathrm{~h}$ ) as a source of food and humidity. The individuals were chosen for the experiments according to body weight; we selected insects with mean body weight $0.14 \mathrm{~g}$ per individual. To avoid the possibility of significant differences between body weight and actual larval stage, only the mealworms reared under the same conditions were used for the experiments.

\section{Substances}

Capsaicin and capsazepine (Sigma-Aldrich) were dissolved in ethyl alcohol. We tested two concentrations of both substances: $10^{-7}$ and $10^{-4} \mathrm{M}$. One group of insects was intoxicated with alcohol only ( $1 \%$ - the same concentration as in the tested substance solutions) to evaluate the effect of the solvent alone. The control group of animals received only water. In each experimental series, the mealworms were given $10 \mu \mathrm{l}$ of the tested substances on the ventral part of the prothorax.

\section{Behavioral thermoregulation}

Temperature preferred by the examined insects was evaluated in a thermal gradient system. The system consists of a long and narrow aluminum trough $(60 \times 5 \mathrm{~cm})$ cooled down by a cryostat on the one end and heated up by a thermostat (Fisherbrand ${ }^{\circledR}$ FBH 612) on the other. In this way, the ambient temperature gradient inside the trough is generated. The temperature in the thermal gradient system ranged from 12 to $40^{\circ} \mathrm{C}$. The thermal gradient system was divided into 20 compartments of equal length and the temperature in each compartment was measured with a thermocouple prior to each experiment. Behavioral thermoregulation of the mealworms after intoxication was recorded for 3 days with a camera (Sony HDR-XR 200VE) and saved on a computer disc. The image from the camera was recorded every 3 min with BioVid program (FERRO Software). We recorded thermal preferences of the animals in the 12-h cycles of light and dark. The mealworms were put into the thermal gradient system immediately after intoxication with the tested substances. In each experimental series, we examined six insects placed together into one thermal gradient system. Each experimental series was repeated six times using different individuals. The mealworms' movements were not restricted in the thermal gradient system and the slices of apples were placed as a source of food and humidity. Slices of apples were placed in different parts of the thermal gradient system with different ambient temperatures $\left(15,22\right.$, and $\left.30^{\circ} \mathrm{C}\right)$ in order not to affect the insects' distribution. Food was exchanged every $24 \mathrm{~h}$.

\section{Data analysis}

The data recorded from the thermal gradient system served for estimating the temperatures preferred by the intoxicated insect. For assessing the effect of the tested substances on thermal preferences of mealworms, one-way analysis of variance (one-way ANOVA) and post hoc Tukey HSD test were performed in PASW Statisitcs 18 (SPSS Inc.) All 
values are presented as mean $\pm \mathrm{SD}$ and the results were considered statistically significant at $P<0.05$.

\section{Results}

The mealworms that received only water (control group) preferred staying at temperatures around $21^{\circ} \mathrm{C}$ during $72 \mathrm{~h}$ of the experiment (mean $20.91 \pm 0.51^{\circ} \mathrm{C}$ ). Application of alcohol alone did not change the thermal behavior of the examined insects significantly $\left(21.47 \pm 0.54^{\circ} \mathrm{C} ; P>0.05\right)$ (Fig. 1).

After intoxication with capsaicin in a concentration of $10^{-7} \mathrm{M}$, an interesting change in behavioral thermoregulation of mealworms was observed. In the first $24 \mathrm{~h}$, the insects preferred lower temperatures than the control animals $\left(18.40 \pm 0.53^{\circ} \mathrm{C} ; P=0.02\right)$ (Fig. 3). In the next 2 days, the examined mealworms chose temperatures similar to the control group (Fig. 1). Capsaicin in a concentration of $10^{-4} \mathrm{M}$ lowered slightly the temperature preferred by the insects during 3 days of experiment $\left(19.57 \pm 0.60^{\circ} \mathrm{C}\right)$, but the changes were not significant $(P>0.05)$ (Fig. 2).
Capsazepine in low concentration $\left(10^{-7} \mathrm{M}\right)$ affected the insects' thermoregulation in an opposite way to capsaicin in low concentration. The mealworms intoxicated with capsazepine preferred staying at warmer parts of the gradient $\left(22.47 \pm 1.27^{\circ} \mathrm{C}\right)$ (Fig. 1), especially in the first $24 \mathrm{~h}$ of the experiment $\left(23.55 \pm 0.78^{\circ} \mathrm{C} ; P=0.001\right)$ (Fig. 3). On the other hand, the insects intoxicated with capsazepine in high concentration $\left(10^{-4} \mathrm{M}\right)$ stayed at the lowest temperatures $\left(18.25 \pm 0.77^{\circ} \mathrm{C}\right)$ (Fig. 2).

\section{Discussion}

Since insects are ectothermic animals, ambient temperature affects profoundly all their physiological processes. For that reason, thermosensation is very important for these organisms. To date, we do not have complete knowledge about the structures involved in the reception of temperatures in insects. The sensilla that respond to warm or cold stimuli are mostly located on insects' antennae. Cold receptors are usually combined with two hygroreceptor cells ('moist' and 'dry' receptor), as reported for example in Apis, Triatoma, Antherea, Carausius, Aedes and Gryllus.
Fig. 1 Temperature preferred $\left({ }^{\circ} \mathrm{C}\right)$ (mean $\pm \mathrm{SE}$ ) by the mealworms intoxicated with alcohol (1\%), capsaicin and capsazepine in a concentration of $10^{-7} \mathrm{M}$
Fig. 2 Temperature preferred $\left({ }^{\circ} \mathrm{C}\right)($ mean $\pm \mathrm{SE})$ by the mealworms intoxicated with alcohol (1\%), capsaicin and capsazepine in a concentration of $10^{-4} \mathrm{M}$
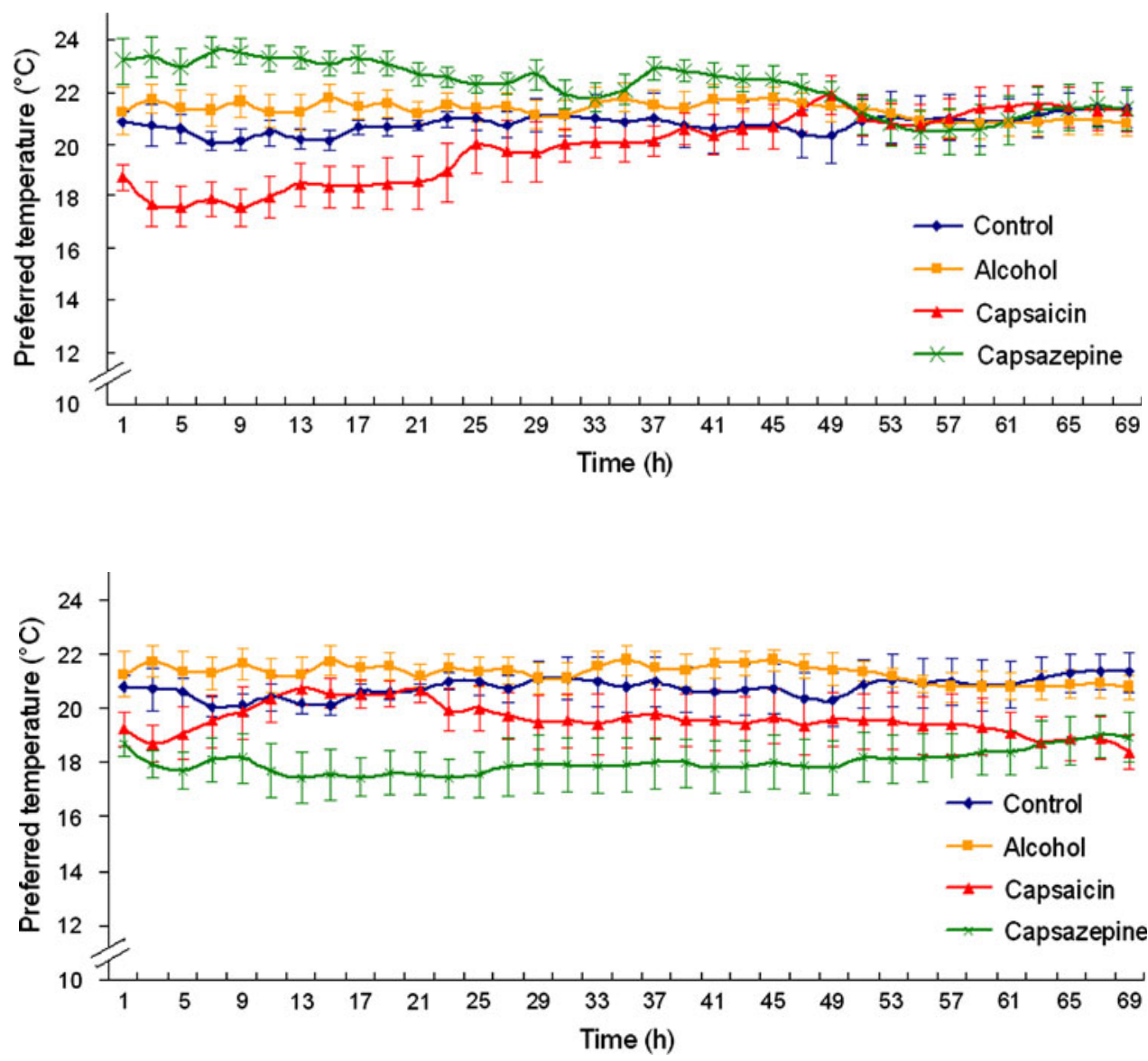


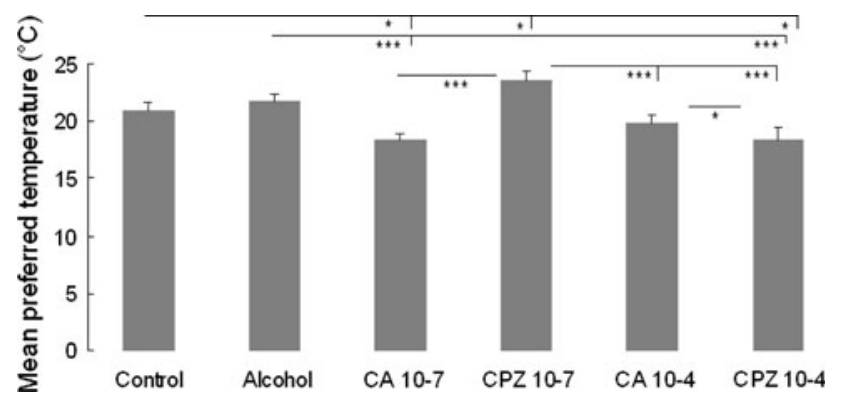

Fig. 3 Mean temperature $\left({ }^{\circ} \mathrm{C}\right)$ preferred in the first $24 \mathrm{~h}$ of experiment by the mealworms intoxicated with alcohol $(1 \%)$, capsaicin (CA) and capsazepine (CPZ) in two concentrations: $10^{-7}$ and $10^{-4} \mathrm{M}$. Lines show statistical significance between series (one-way ANOVA; post hoc Tukey HSD test): $* * * P<0.001$; $* * P<0.01$; $* P<0.05$

In some insect species, such as Periplaneta, Locust and Leucophaea, there is an additional type of cold receptor combined with olfactory receptors in the antennal olfactory and thermoreceptive sensillum. Two kinds of thermoreceptors (warm and cold) associated with mechanoreceptive hairs were reported in Speophyes (Steinbrecht and Müller 1991; Nishikawa et al. 1992; Gingl and Tichy 2001). Gallio et al. (2011) revealed that in Drosophila, two antennal structures (arista and sacculus) contain hot and cold receptors. These thermoreceptors project onto anatomically and functionally distinct glomeruli in the proximal antennal protocerebrum of the fly's brain. The preferred temperature is suggested to be set by independent action of hot and cold receptor systems. The authors demonstrated that members of the TRP family belonging to TRPP (polycistin) subfamily Brivido TRP (Brv 1, 2 and 3) might function as antennal cold receptors. Also, other transient receptor potential family members involved in insects' temperature sensation are known. The first known receptor involved in nociception of noxious temperatures in Drosophila was Painless, a member of the TRPA subfamily (Tracey et al. 2003). Other TRPA channels involved in Drosophila reception of warm temperatures are Pyrexia, activated by temperatures above $40^{\circ} \mathrm{C}$ (Lee et al. 2005), and dTRPA1, important for thermotaxis (Rosenzweig et al. 2005). Rosenzweig et al. (2008) identified receptors required for cold avoidance in fruit fly. There are also members of TRP family that form a different subfamily (TRPC): TRP and TRPL, which are also implicated in phototransduction. It is notable that although TRP receptors take part in thermosensation both in insects and mammals, the sensation of different ambient temperatures is mediated by different channels in those groups of animals. In insects, the members of the TRPA subfamily are warm activated, while the mammalian TRPA channel is responsible for reception of low temperatures. Mammalian TRPV channels were implicated in sensing warm temperatures, while insect
TRPV channels, Nanchung and Inactive, expressed in Chinese hamster ovary tissue culture cells, were not activated by temperature (Liedtke and Kim 2005). Recent research showed, however, that in Drosophila larvae Inactive is required for the selection of preferred $\left(17.5^{\circ} \mathrm{C}\right)$ over cooler temperatures $\left(14-16^{\circ} \mathrm{C}\right)$, implying it takes part in insects' thermoregulation (Kwon et al. 2010). Despite the fact that mammalian TRPV1 is activated by capsaicin, we do not have any direct evidence for capsaicin sensitivity of TRPV channels in insects. Kim et al. (2003) reported that in heterologous expression systems, Chinese hamster ovary cells expressing Nanchung channels were unresponsive to capsaicin. A similar situation occurred with Inactive, the second insect TRPV (Gong et al. 2004). It is suggested that capsaicin sensitivity of TRPV1 is a recent evolutionary acquisition in mammals, as avian vanilloid receptor shows only residual sensitivity to this substance (Jordt and Julius 2002). Although insect vanilloid receptors do not respond to capsaicin, there are reports that this substance may repel some insect species. Capsaicin is used as a repellent against cotton pests and one species of storedproducts beetle (Sitophilus zeamais) (Spurr and McGregor 2003). This shows that at least some insect species are sensitive to capsaicin, although it does not clearly imply that they possess receptors sensitive to capsaicin. The studies conducted at our laboratory on cockroaches revealed that insects respond to mammalian TRPV1 agonist, capsaicin, which affects their behavioral thermoregulation. However, we did not investigate insects' reaction to capsazepine then. In the presented research, we hypothesized that capsaicin and capsazepine affect insects' thermoregulation through receptors functionally similar to the mammalian TRPV1 channel. The experiments performed on mealworms in the thermal gradient system seem to confirm our assumptions. The larvae intoxicated with capsaicin in low concentration $\left(10^{-7} \mathrm{M}\right)$ in the first $24 \mathrm{~h}$ of the experiments preferred temperatures lower by about $2-3^{\circ} \mathrm{C}$ than the control group. This behavior is quite similar to the one observed in mammals. Subcutaneous injection of capsaicin $(5 \mathrm{mg} / \mathrm{kg})$ to rats induced cutaneous vasodilation, increase of skin temperature and decrease of body temperature leading to hypothermia that lasted for about $2 \mathrm{~h}$. Simultaneously, capsaicin increased rats' oxygen consumption and heat production, which in turn resulted in hyperthermia that occurred after hypothermia (Kobayashi et al. 1998).

Capsazepine (in low concentration), a TRPV1 antagonist, elicited an opposite reaction in the examined insects. The mealworms stayed at warmer parts of the thermal gradient system than the control animals for almost $45 \mathrm{~h}$ from intoxication, and then moved to the temperatures similar to the ones chosen by the larvae which were not intoxicated. In mammals, the application of various TRPV1 antagonists (except capsazepine) induces an 
increase in body temperature (Gavva et al. 2007). It is suggested that hyperthermia appears because TRPV1 receptors are tonically active in vivo, keeping body temperature at normal level, and when antagonists block TRPV1 channel, the body temperature increases. Although capsazepine blocks mammalian TRPV1 and was used in thermoregulation studies in rats and mice, it was not shown that this substance causes hyperthermia. TRPV1 has a different gating mechanism for protons, heat and vanilloids. It was reported that capsazepine does not block activation of vanilloid receptor subtype 1 by low $\mathrm{pH}$, which presumably may be the reason for it not causing hyperthermia (Romanovsky et al. 2009). Since in insects, hemolymph $\mathrm{pH}$ may change in a broader range than in mammals (the reported hemolymph $\mathrm{pHs}$ in insects range from 6.4 to 7.5; Harrison 2001), insects vanilloid receptor may vary in reaction to protons.

Here, we report that capsazepine in a concentration of $10^{-7} \mathrm{M}$ affects insect behavioral thermoregulation, inducing selection of warm temperatures. The observed opposite effect of capsaicin and capsazepine in the same concentration on the mealworms' thermoregulation may suggest that the tested substances act as agonist-antagonist presumably on the same structure. We suppose that this may be a receptor functionally similar to mammalian TRPV1.

As far as higher concentration $\left(10^{-4} \mathrm{M}\right)$ of the tested substances is concerned, the observed changes in the mealworms' behavioral thermoregulation are similar for capsaicin and capsazepine. The insects stayed at cooler parts of the thermal gradient system than the group of insects not intoxicated. Lundbaek et al. (2005) showed that capsaicin acts through TRPV1 only at submicromolar concentrations, whereas at micro- to millimolar concentrations this substance alters the physical properties of biological membranes. Capsaicin adsorbs to lipid bilayers and affects inter alia membrane fluidity, causing a decrease in its stiffness. This process leads to changes in functioning of many membrane proteins, and similar action is observed after capsazepine in micro- to millimolar concentrations. Our previous studies revealed that in the thermal gradient system the Colorado potato beetle (Leptinotarsa decemlineata Say) larvae fed on red pepper chose ambient temperatures higher by $10^{\circ} \mathrm{C}$ than the larvae fed on potatoes (Tęgowska et al. 2005). It is very interesting to observe a distinct reaction of insects exposed to pure capsaicin (mealworms) or red pepper (Colorado potato beetles).

The observed changes in insects' behavioral thermoregulation may stem from the increased membrane fluidity caused by the examined substances (at higher concentration, $10^{-4} \mathrm{M}$ ). When the lipid bilayer stiffness is decreased, the insect may choose cooler ambient temperatures to restore regular fluidity of the membrane. Since we did not examine the changes in the insects' lipid bilayer fluidity after capsaicin or capsazepine application, we cannot be sure whether the observed behavior of the mealworms resulted from these or other reasons.

It is remarkable that capsaicin affects not only mammalian, but also insect, thermoregulation. The observed opposite effect of TRPV1 agonist and antagonist on insect behavioral thermoregulation, which at the same time remains similar to the effect of these substances on thermoregulation in mammals, indicates indirectly that capsaicin may act on receptors in insects that are functionally similar to TRPV1. However, it cannot be excluded that the observed results reflect non-specific actions unrelated to TRP channels. Further investigations are required to explain through what way TRPV1 agonist and antagonist influence behavioral thermoregulation of insects.

Acknowledgments This research was funded by Nicolaus Copernicus University Grant number 309B and by the Ministry of Science and Higher Education Grant number 3039/B/P01/2008/34. The authors thank the two anonymous reviewers for many helpful comments and suggestions that greatly improved this manuscript.

Open Access This article is distributed under the terms of the Creative Commons Attribution Noncommercial License which permits any noncommercial use, distribution, and reproduction in any medium, provided the original author(s) and source are credited.

\section{References}

Adamkiewicz B, Grajpel B, Tęgowska E (2008) Wpływ kapsaicyny na czynność spontaniczną neuronów DUM oraz preferencje termiczne Periplaneta americana L. In: Gabrielska J, Misiak P (ed) Materials of the conference Błony biologiczne 16-18 May 2008, Szklarska Poręba, pp 125-128

Benham CD, Gunthorpe MJ, Davis JB (2003) TRPV channels as temperature sensors. Cell Calcium 33:479-487

Caterina MJ (2007) Transient receptor potential ion channels as participants in thermosensation and thermoregulation. Am J Physiol Regul Integr Comp Physiol 292:64-76

Caterina MJ, Schumacher MA, Tominaga M, Rosen TA, Levine JD, Julius D (1997) The capsaicin receptor: a heat-activated ion channel in the pain pathway. Nature 389:816-824

Clapham DE (1997) Some like it hot: spicing up ion channels. Nature 389:783-784

Dhaka A, Viswanath V, Patapoutian A (2006) TRP ion channels and temperature sensation. Annu Rev Neurosci 29:135-161

Dillon ME, Wang G, Garrity PA, Huey RB (2009) Thermal preference in Drospohila. J Thermal Biol 34:109-119. doi: 10.1016/j.jtherbio.2008.11.007

Gallio M, Ofstad TA, Macpherson LJ, Wang JW, Zuber CS (2011) The coding of temperature in the Drosophila brain. Cell 144:614-624

Gavva NR, Bannon AW, Surapaneni S, Hovland DN Jr, Lehto SG, Gore A, Juan T, Deng H, Han B, Klionsky L, Kuang R, Le A, Tamir R, Wang J, Youngblood B, Zhu D, Norman MH, Magal E, Treanor JJS, Louis J-C (2007) The vanilloid receptor TRPV1 is tonically activated in vivo and involved in body temperature regulation. J Neurosci 27:3366-3374 
Gingl E, Tichy H (2001) Infrared sensitivity of thermoreceptors. J Comp Physiol A 187:467-475

Gong Z, Son W, Chung YD, Kim J, Shin DW, McClung CA, Lee Y, Lee H, Chang D-J, Kaang B-K, Cho H, Oh U, Hirsh J, Kernan MJ, Kim C (2004) Two interdependent TRPV channel subunits, Inactive and Nanchung, mediate hearing in Drosophila. J Neurosci 24:9059-9066

Harrison JF (2001) Insect acid-base physiology. Annu Rev Entomol 46:221-250

Jordt SE, Julius D (2002) Molecular basis for species-species sensitivity to "hot" chili peppers. Cell 108:421-430

Kim J, Chung YD, Park D, Choi S, Shin DW, Soh H, Lee HW, Son W, Yim J, Park CS, Kernan MJ, Kim C (2003) A TRPV family ion channel required for hearing in Drosophila. Nature 424: $81-84$

Kobayashi A, Osaka T, Namba Y, Inoue S, Lee TH, Kimura S (1998) Capsaicin activates heat loss and heat production simultaneously and independently in rats. Am J Physiol Regulatory Integrative Comp Physiol 275:92-98

Kwon Y, Shen WL, Shim HS, Montell C (2010) Fine thermotactic discrimination between the optimal and slightly cooler temperatures via a TRPV channel in chordotonal neurons. J Neurosci 30:10465-10471

Lee Y, Lee Y, Lee J, Bang S, Hyun S, Kang J, Hong S-T, Bae E, Kaang B-K, Kim J (2005) Pyrexia is a new thermal transient receptor potential channel endowing tolerance to high temperatures in Drosophila melanogaster. Nat Genet 37:305-310

Liedtke W, Kim C (2005) Functionality of the TRPV subfamily of TRP ion channels: add mechano-TRP and osmo-TRP to the lexicon!. Cell Mol Life Sci 62:2985-3001

Lundbæk JA, Birn P, Tape SE, Toombes GES, Søgaard R, Koeppe RE II, Gruner SM, Hansen AJ, Andersen OS (2005) Capsaicin regulates voltage-dependent sodium channels by altering lipid bilayer elasticity. Mol Pharmacol 68:680-689

McKemy DD (2007) Temperature sensing across species. Pflugers Arch Eur J Physiol 454:777-791

Nishikawa M, Yokohari F, Ishibashi T (1992) Response characteristic of two types of cold receptors on the antennae of the cockroach, Periplaneta americana L. J Comp Physiol A 171:299-307
O'Neil RG, Brown RC (2003) The vanilloid receptor family of calcium-permeable channels: molecular integrators of microenvironmental stimuli. News Physiol Sci 18:226-231

Olszewska J (2010) Vanilloid receptors-comparison of structure and functions in mammals and invertebrates. Folia biologica (Cracow) 58:1-7. doi:10.3409/fb58_1-2.01-07

Patapoutian A (2005) TRP channels and thermosensation. Chem Senses 30:193-194

Romanovsky AA, Almeida MC, Garami A, Steiner AA, Norman MH, Morrison SF, Nakamura K, Burmeister JJ, Nucci TB (2009) The transient receptor potential vanilloid-1 channel in thermoregulation: a thermosensor it is not. Pharmacol Rev 61:228-261

Rosenzweig M, Brennan KM, Tayler TD, Phelps PO, Patapoutian A, Garrity PA (2005) The Drosophila ortholog of vertebrate TRPA1 regulates thermotaxis. Genes Dev 19:419-424

Rosenzweig M, Kang K, Garrity PA (2008) Distinct TRP channels are required for warm and cool avoidance in Drosophila melanogaster. PNAS 103:14668-14673

Spurr EB, McGregor PG (2003) Potential invertebrate antifeedants for toxic baits used for vertebrate pest control. Sci Conserv 232:13

Steinbrecht RA, Müller B (1991) The thermo-/hygrosensitive sensilla of the silkmoth, Bombyx mori: morphological changes after dryand moist-adaptation. Cell Tissue Res 226:441-456

Szallasi A, Blumberg PM (1999) Vanilloid (capsaicin) receptors and mechanisms. Pharmacol Rev 51:160-211

Tęgowska E, Grajpel B, Piechowicz B (2005) Does red pepper contain an insecticidal compound for Colorado beetle? IOBC wprs Bulletin 28:121-127

Tracey DW, Wilson RI, Laurent G, Benzer S (2003) painless, a Drosophila gene essential for nociception. Cell 113:261-273

Vennekens R, Owsianik G, Nilius B (2008) Vanilloid transient receptor potential cation channels: an overview. Curr Pharm Des 14:18-31

Walpole CSJ, Bevan S, Bovermann G, Boelsterli JJ, Breckenridge R, Davies JW, Hughes GA, James I, Oberer L, Winter J, Wrigglesworth R (1994) The discovery of capsazepine, the first competitive antagonist of the sensory neuron excitants capsaicin and resiniferatoxin. J Med Chem 37:1942-1954 